\title{
O ENSINO DE FILOSOFIA COMO DESPERTAR DO ESPÍRITO DE CRIATIVIDADE
}

\author{
Renato Nunes Bittencourt (1)
}

Resumo: Este artigo pretende abordar a importância do ensino de Filosofia para a formação intelectual do jovem estudante, pelo fato de possibilitar o desenvolvimento do senso crítico nas suas mais diversas manifestações. Ressalto também o caráter de criatividade que está presente na reflexão filosófica, pois tal prática se consolida como uma doação de significados e valores por parte daquele que filosofa.

\section{Introdução}

A questão da obrigatoriedade da presença da disciplina de Filosofia na estrutura curricular do Ensino Médio brasileiro, tema discutido amplamente por importantes pesquisadores e educadores dedicados com o aprimoramento deste âmbito, decorre da compreensão da importância capital da reflexão filosófica para a formação da consciência crítica do indivíduo, assim como da necessidade da compreensão adequada dos fundamentos epistemológicos dos demais ramos do conhecimento, os quais, nas suas origens, manifestam explicitamente uma grande dívida para com a Filosofia. Desse modo, uma das justificativas mais pertinentes para a inclusão incondicional da disciplina de Filosofia nas instituições educacionais do Brasil decorre justamente do anseio pela efetiva superação da fragmentação dos saberes tradicionais, os quais, com a delimitação cada vez mais rigorosa dos seus conteúdos epistêmicos, favorecem apenas que ocorra a "especialização máxima do mínimo" por parte do pesquisador, uma vez que esses saberes perderam efetivamente o vínculo interativo existente entre os ramos de conhecimento de modo muito adequado nas eras longínquas.

Inclusive, ressalto que é fato não muito difícil de comprovar que, durante longo tempo, esteve em vigência nas nossas escolas uma metodologia de ensino rigorosamente delimitada na interpretação estrita de determinada disciplina, sem que porventura houvesse a mínima preocupação por parte da estrutura pedagógica de se contextualizar os saberes, assim como de realizar uma interação entre os mesmos, através da prática da interdisciplinalidade, tendência essa que se desenvolve em importantes núcleos educacionais brasileiros. Contudo, a situação da Filosofia, nessas circunstâncias, é extremamente problemática, pois, em seus primórdios, ela agregava consigo os mais diversos ramos do conhecimento, os quais, ao longo da história do saber, se emanciparam do seu caráter global. Aliás, devemos ressaltar que a Filosofia é considerada como uma espécie de fundamento primordial das diversas áreas do conhecimento, intitulação esta que pode ser justificada pelo fato, anteriormente citado, da situação original da Filosofia como a agregadora matriz dos diversos ramos do saber. Desse modo, a importância do ensino de Filosofia, numa perspectiva epistemológica, decorre da sua relação com 
os fundamentos das ciências, os quais, devemos ressaltar, muitas vezes, são incompreendidos pelos professores, que se preocupam tão somente com a aplicação de fórmulas, sem que se investigue os fundamentos, as origens dos saberes, as motivações criativas do gênio inovador, dentre outras possibilidades. Consequentemente, nessas condições, a formação adequada do estudante também é sensivelmente prejudicada, problema esse que decorre diretamente da inaptidão do professor em proporcionar a investigação acerca da natureza teórica do conhecimento fatual, tarefa que o ensino de Filosofia possibilita perfeitamente, quando utilizada de maneira coerente com as suas próprias características, ou seja, exercitar o ato de pensar por parte do indivíduo de modo que este desenvolva uma compreensão global acerca do real, evitando-se assim a formação de idéias preconcebidas.

Contudo, devemos ressaltar que a função do ensino de Filosofia nas instituições de formação não se restringe apenas ao ato de refletir os princípios teóricos das ciências, posto que, desse modo, as potencialidades do uso da Filosofia seriam restringidas apenas ao ato de se fornecer o esclarecimento adequado de conceitos científicos. A perspectiva filosófica realmente favorece a elucidação do saber, mas, no entanto, ela não se reduz apenas ao exercício dessa função. A Filosofia também deve ser compreendida como uma atividade, um posicionamento por parte do pesquisador, tanto no ponto referente ao seu modo de interpretar o mundo, como também no modo de viver efetivamente no mundo. Portanto, a Filosofia mantém estreito vínculo com a criatividade singular. Vejamos então, a seguir, uma tentativa de justificar essa hipótese, diferindo, primeiramente, a reflexão filosófica da análise científica, assim como a situação da Filosofia nos tempos atuais.

\section{As peculiaridades do ato de filosofar}

A reflexão filosófica se torna de suma importância para a formação intelectual do jovem indivíduo, do estudante, a partir do momento em que ela serve de estímulo para a investigação do significado da realidade por parte daquele. Afinal, a Filosofia se caracteriza sobretudo por sua compreensão global em relação ao mundo circundante, como uma espécie de visão ampla acerca dos fatos cotidianos. Enquanto uma ciência da natureza lida adequadamente com os objetos do modo muito minucioso e rigorosamante descritivo, para que possa recolher do mesmo as informações que serão compiladas nos resultados das pesquisas, o pensamento filosófico se preocupa, ao analisar e interpretar um determinado objeto, compreender a sua possibilidade de significados, considerando este, no entanto, não como um fenômeno geral, abstrato, mas particular, concreto. Nesse ponto, portanto, ela se distingue da análise científica, pois, ainda que investigue a natureza do objeto particular, pretende, a partir deste, realizar inferências universais, acerca dos demais objetos similares. Desse modo, a ciência, para facilitar a assimilação dos seus conteúdos epistêmicos e, mais ainda, para a compreensão adequada de seus dados por parte da comunidade de investigadores, retira, de um dado gênero ou espécie, os seus caracteres singulares, as diferenças, em prol da afirmação de um suposto sujeito universal, puro, tal como um arquétipo. Algumas correntes filosóficas se caracterizaram no passado por adotarem uma postura similar ao método de investigação científica em relação ao problema da pluralidade e 
multiplicidade de objetos e de entes, fato este que excluía justamente do objeto conhecido tudo aquilo que fosse discrepante em relação aos demais. Essa perspectiva, portanto, criava uma espécie de objeto ideal, excluindo assim qualquer valorização da análise do conhecimento em relação ao dado particular.

Contudo, a Filosofia em nossos tempos demonstra uma revalorização do múltiplo, do singular, em relação ao ideal, ao universal, talvez como decorrência da compreensão de que o homem é um ser contingente, mais precisamente no sentido de que sua vida não é determinada de modo a-histórico, ou seja, sem a sua intervenção no mundo concreto através da sua ação. Afinal, o homem se encontra em um processo de transformação contínua, que se manifesta de acordo com o próprio rumo adotado nas suas mais diversas ações. Dessa maneira, é instaurada uma perspectiva que se pauta na legitimação do caráter singular do homem, da diferença. Nessas circunstâncias, torna-se uma grave incompreensão acerca das características da natureza humana a tendência de se considerar a idéia de igualdade entre os homens, ao nível existencial e educacional, sobretudo. Podemos dizer que a criatividade não se manifesta de modo homogêneo na totalidade dos indivíduos, mas plenamente de acordo com as características singulares de cada ser humano, criatividade essa que pode ser instigada pelo educador, para que o indivíduo manifeste do modo mais livre possível o seu potencial.

Podemos considerar que a Filosofia, caracterizando-se sobretudo pelo estímulo $e$ dedicação ao ato de pensamento e de reflexão crítica, favorece sensivelmente a formação da criatividade do indivíduo que desenvolve, na sua vida, um vínculo entre ação e consciência filosófica de mundo. Afinal, a atividade filosófica genuína pretende auxiliar ao homem no aprimoramento das suas faculdades intelectuais, livrando a sua ordem de pensamento das opiniões arraigadas na dimensão anônima do senso comum, na repetição irrefletida dos discursos, dentre outras possibilidades similares de problemas que exterminam lentamente a cultura autêntica. A reflexão filosófica encoraja o indivíduo a pronunciar publicamente aquilo que ele pensa ou sente, possibilitando o aprimoramento deste discurso, se porventura ele estiver preenchido por lugares comuns, adquiridos passivamente ao longo do contato cotidiano do homem na sua sociedade. Trata-se, portanto, de um exercício extremamente necessário para que o indivíduo venha a compreender os valores de sua singularidade pessoal, afirmando a sua potencialidade criativa de modo independente da ordem de mundo da apreciação massificada.

Quando se discutia a pertinência do ensino de Filosofia para os jovens, sobretudo no Ensino Médio (e, em algumas circunstâncias especiais, até mesmo para as crianças), alguns filósofos acadêmicos conservadores demonstravam pouca preocupação com essa questão, uma indiferença indigna da própria condição de filósofo, talvez por preferirem manter dedicação exclusiva aos interesses do ensino universitário, tanto no nível da graduação como da pós-graduação. Geralmente, quando se pronunciavam publicamente acerca do ensino de Filosofia para os jovens, demonstravam um posicionamento contrário, considerando inclusive que os adolescentes ainda não possuem maturidade intelectual para a assimilação $e$ reflexão de temas filosóficos. Uma opinião desse nível deve ser considerada como 
um grande absurdo, pois denota uma série de problemas que somente prejudicam a própria presença da Filosofia na vida cotidiana da sociedade:

- 1. Por qual motivo a Filosofia porventura seria uma disciplina que requer do estudante a presença de uma suposta maturidade intelectual? Se validarmos esse argumento, teríamos que considerar também que as outras disciplinas ministradas nas escolas necessitariam do pré-requisito de que os estudantes sejam dotados dessa pretensa maturidade intelectual, para que tais conteúdos sejam por eles compreendidos do modo mais adequado possível. Essa indagação, inclusive, gera uma outra, entrelaçada diretamente com a precedente: qual o motivo de se acreditar na necessidade da maturidade intelectual para o ato de pensar filosoficamente, enquanto em outras atividades do conhecimento, essa maturidade supostamente não seria necessária? Essa perspectiva manifesta uma postura sectária em relação aos demais ramos do conhecimento, pois, ao invés de vislumbrar justamente a integração da atividade filosófica com as demais ciências, procura, pelo contrário, a sua completa separação. A diferença entre o pensamento filosófico e o pensamento científico propriamente dito ocorre apenas no nível conceitual, no método utilizado para a investigação da realidade do mundo, pois, tanto a Filosofia, quanto uma ciência aplicada como a Física, por exemplo, podem fornecer hipóteses acerca do fundamento da realidade, cada umas, das quais, obviamente, de acordo com suas peculiaridades naturais.

- 2. Se porventura o jovem não tiver a oportunidade de entrar em contato com a Filosofia através do estudo, digamos, no próprio Ensino Médio, quando tal circunstância ocorrerá? Afinal, o estudante que manifesta interesse pela Filosofia, sobretudo em relação ao curso de graduação oferecido pelas principais universidades brasileiras, em algum momento de sua vida necessariamente teve a oportunidade de entrar em contato com as obras e com os temas elaborados por determinado pensador. Afinal, as idéias filosóficas não surgem do vazio, do "ponto zero", existindo sempre um ponto de partida, uma etapa inicial, pela qual o aspirante ao estudo de Filosofia desenvolverá os seus primeiros passos nessa senda fascinante. Devemos salientar que, obviamente, alguns indivíduos, em virtude da convergência dos mais diversos fatores, demonstram, em algumas circunstâncias, um interesse muito intenso da reflexão de temas de natureza essencialmente filosófica, tais como: o questionamento acerca do princípio das coisas e do próprio mundo; o modo de agir para com os demais; a idéia de alma, de Deus, dentre outras questões. No entanto, os filósofos conservadores demonstram o desconhecimento prático de que essas questões não brotam na mente do indivíduo que se encontra no ato de filosofar tal com uma espécie de iluminação proveniente de uma sabedoria superior, que escolhe arbitrariamente alguns eleitos para que estes venham a portar o cajado da autoridade filosófica, quando este grande "selecionado" ingressar na faculdade de Filosofia. O interesse pela reflexão filosófica surge da própria interação do indivíduo com o mundo, com a sociedade e suas manifestações culturais, de modo que, a partir desse contato primordial com a realidade externa, o indivíduo procura 
compreender o sentido da mesma. Por mais que um indivíduo manifeste pouca afeição pela reflexão, pelo exercício de questionamento, em algum momento da sua vida certamente ele buscou alcançar a compreensão do sentido do mundo.

Se porventura realizarmos uma espécie de estatística sobre o interesse da população brasileira alfabetizada pela reflexão filosófica, certamente constataremos que grande maioria demonstrará uma completa aversão por ela, devido sobretudo ao grande mal-estar que o pensamento filosófico motiva nas cabeças desprovidas de senso crítico, cabeças essas que consideram o exercício de pensamento como algo cansativo, tedioso, preferindo assim apenas repetir os discursos prontos, alardeados no cotidiano da sociedade. Desse modo, a atividade filosófica se caracteriza tradicionalmente pelo fato de receber, por parte das massas, as mais pejorativas denominações, tais como "pouco prática", "pura viagem", "pouco lucrativa". Assim, constataremos que apenas uma pequena parcela da comunidade dos estudantes brasileiros que travaram contato com a Filosofia desenvolve um interesse concreto por ela, através de pesquisas, leituras consistentes, debates, dentre outras oportunidades de manifestações de atividades filosóficas. Por outro lado, grande parcela, infelizmente, não consegue desenvolver um vínculo entre a vida individual e a reflexão filosófica, que pode ser articulada com as mais importantes questões da realidade cotidiana.

Defender a exclusão do ensino de Filosofia para os jovens demonstra uma terrível incompreensão, por parte dos "burocratas do ensino" (2) e dos filósofos conservadores, dos problemas culturais e sociais que se manifestam na nossa realidade, pois denota uma espécie de sentimento de obscurantismo acerca da transmissão de conhecimento. Esse tipo de posicionamento demonstra ainda a mesquinharia de algumas correntes intelectuais, que manifestam claramente uma aversão pela divulgação democrática do conhecimento. Versemos mais uma vez acerca das peculiaridades da população brasileira alfabetizada: em sua grande maioria, ela se caracteriza negativamente pelo reduzido hábito da leitura por parte dos seus membros, fato este absolutamente prejudicial para a formação do senso crítico do ser humano, pois desacostuma o indivíduo a compreender as idéias produzidas pelos intelectuais e escritores, realizando, quando necessário, críticas consistentes em relação àqueles, evidenciando assim a assimilação do texto estudado. Para um indivíduo parcamente envolvido com o hábito de ler e de pensar, os textos mais ínfimos, os opúsculos, se tornam provas de paciência extraordinária, de modo que ele pode, inclusive, sofrer grandes transtornos para compreender o significado central do texto analisado. Afinal, tal tipo de indivíduo, que raramente se aventura a estudar uma obra com diligência, expõe cruamente a falta de hábito da dedicação e da interpretação pela leitura quando se encontra na necessidade premente de estudar os conteúdos de um texto.

É realmente lamentável que muitos filósofos acadêmicos não manifestem a importância da reflexão filosófica na sociedade, pois trata-se de um tipo de pensamento que favorece a formação do senso crítico, a apuração do gosto estético, o desenvolvimento da consciência do indivíduo como ser social, pois a Filosofia, ao contrário do que pensa erroneamente o senso comum, não é um 
alheamento do mundo, mas a possibilidade de intervenção e de ação efetiva no próprio mundo. Mesmo os filósofos que manifestam em seus escritos um ideal de distanciamento do mundo redigiriam importantes considerações sobre a conduta ética e social do homem. Portanto, o pensamento filosófico é um instrumento que pode ser utilizado pelo indivíduo em prol de seu aprimoramento pessoal e, numa perspectiva maior, para o desenvolvimento de relações sociais plenamente ativas entre os membros de uma comunidade, pois, nestas circunstâncias, cada indivíduo adquire consciência de seu próprio potencial, favorecendo assim o estabelecimento de interações adequadas para a manutenção e crescimento harmônico da coletividade.

Uma vez que a atividade filosófica manifesta claramente os seus benefícios para aquele que nela se insere efetivamente, podemos considerar que é um obscurantismo mesquinho e inconsequente excluir da estrutura do ensino de formação a Filosofia como disciplina, seja por motivações econômicas, seja por razões políticas. Se porventura for por razões econômicas, ou seja, como uma maneira de se evitar despesas na estrutura escolar com a contratação de novos professores, denota muito claramente, por parte dos diretores dos estabelecimento de ensino, que estes não estão preocupados com a formação cultural do jovem, mas apenas com questões financeiras, ou, em outras palavras, com o acúmulo de capital através da venda da cultura. Muitos diretores de escolas alegam que a presença da disciplina de Filosofia na estrutura curricular das suas instituições aumentaria os gastos monetários para a manutenção da mesma, preferindo então excluir da escola a Filosofia enquanto disciplina aplicada. Afinal, infelizmente alguns diretores de estabelecimentos de ensino pensam o problema da educação não como um problema cultural, do âmbito da formação intelectual do ser humano, mas como um problema meramente financeiro, um meio de se obter lucro. Esses diretores administram o sistema educacional brasileiro através de um viés quantitativo, e não, como seria mais adequado, qualitativo, da ordem da própria transmissão do conhecimento e da formação educacional plena do indivíduo.

Vejamos agora a outra possibilidade de exclusão da Filosofia da escola: a Filosofia é uma atividade que requer dedicação, paciência, hábito de leitura e, principalmente, senso crítico em relação ao conjunto de conhecimentos abordados no cotidiano por parte do indivíduo. Desse modo, aquele que pensa filosoficamente os problemas do mundo adquire uma ampla compreensão da sociedade. Ora, devemos compreender que, numa sociedade comandada por homens políticos que em verdade se manifestam contrariamente ao desenvolvimento do conhecimento e da cultura, qualquer tipo de saber que leve o indivíduo ao ato de pensar criticamente, certamente não será bem vista pela estrutura política que controla o Estado. Isso justifica a perseguição que a Filosofia, os demais saberes críticos e os artistas engajados sofrem por parte dos governos ditatoriais. (3) Geralmente, essas sociedades são marcadas pela exacerbação da tecnocracia, pois o anseio desmedido pela produtividade industrial instiga os seus membros a utilizarem as suas forças em atividades técnicas, altamente especializadas, caracterizadas, contudo, por requererem do indivíduo não o desenvolvimento do pensamento crítico, mas a concentração na execução de 
atividades precisas. Afinal, a Filosofia comprometida com a criação e a contestação da ordem vigente é a "má consciência" de seu tempo, de sua sociedade, pautada apenas na repetição irrefletida de uma ideologia. O filósofo comprometido com a elevação do nível de conhecimento e da cultura de seu povo não coaduna, em hipótese alguma, com as disposições contrárias ao uso adequado da razão e do desenvolvimento feliz de seus membros. Portanto, a atividade filosófica requer um relativo grau de intempestividade por parte do pensador, pois ele é a voz crítica que se insurge contra os valores decadentistas da sua sociedade.

\section{A Filosofia e o seu vínculo com criatividade}

Após versar acerca da importância da Filosofia na vida social e na formação educacional dos jovens, penso que seria pertinente refletir sobre aquela que seria a metodologia mais interessante a ser desenvolvida pelo professor no curso de Filosofia do Ensino Médio. É comum que os professores adotem comumente uma leitura histórica dos textos dos grandes filósofos, interpretando os principais conceitos presentes nas obras desses autores. Podemos considerar essa perspectiva pertinente, quando o professor favorece a compreensão da visão de mundo desenvolvida pelo filósofo abordado, contextualizando os temas primordiais que estão presentes nessas obras, tais como as hipóteses acerca do fundamento primordial da natureza, a idéia de virtude, de belo, dentre outras questões. Desse modo, uma leitura histórica dos textos filosóficos deve privilegiar a reflexão sobre os grandes temas presentes ao longo da tradição, evitando que a obra do autor estudado se encerre em si mesma, o que criaria uma espécie de dogma sobre o nome e o pensamento do filósofo, contradizendo assim a própria natureza do conhecimento filosófico. Inclusive, essa perspectiva é a mais privilegiada pelos professores no ensino de Filosofia no âmbito da escola, sobretudo pelo pouco destaque concedido pelas estruturas curriculares às atividades de natureza filosófica, de modo que o professor se encontra na grande dificuldade de desenvolver um trabalho pedagógico adequado e consistente com os estudantes de sua classe. Por conseguinte, o professor privilegia a leitura dos principais tópicos característicos de cada filósofo, fato este que, em virtude da precariedade da presença da disciplina de Filosofia nas escolas brasileiras, torna a interpretação do texto filosófico muito próxima do método de leitura de uma disciplina como a Literatura, por exemplo. Isso não quer dizer que o texto de natureza essencialmente literária não possua o seu caráter de complexidade, afirmação que seria um grande absurdo, pois os grandes escritores e poetas sempre inseriram, nas suas obras, considerações sobre temas caracteristicamente filosóficos. Contudo, um estudante, ao se deparar com a obra de um romancista, por exemplo, não adotará a leitura "ruminante", ou seja, a decifração detalhada dos conceitos presentes na obra. A leitura de um romance ocorre em um fluxo mais livre. Todavia, esse método, inserido na disciplina de Filosofia, salvo em circunstancias especiais, pode se tornar um tanto prejudicial no estudo do texto do pensador, pois sobrepuja a complexidade intrínseca que se encontra presente na obra analisada. Portanto, em diversas circunstâncias, o problema do estudo de Filosofia na escola decorre do parco tempo que é concedido ao professor para que este possa ministrar o seu curso do modo mais adequado possível. 
Outra possibilidade de grande pertinência a ser desenvolvida no estudo da Filosofia entre os jovens reside na reflexão sobre os temas nevrálgicos da visão filosófica de mundo, privilegiando o enxerto de tópicos que favorecem o desenvolvimento de questões reflexivas. Esse método realiza "recortes" nas obras dos filósofos abordados, através de uma orientação de uma proposta que possibilita uma maior liberdade pedagógica para o professor, inclusive, utilizando outros recursos didáticos, como filmes, peças teatrais, obras literárias, cujos conteúdos manifestem uma relação de idéias com o tema filosófico estudado, servindo assim tanto de esclarecimento, como de enriquecimento conceitual do mesmo. Geralmente, esse método é desenvolvido de forma mais coesa e adequada em escolas que se caracterizam pedagogicamente pela concessão de um amplo espaço para a o desenvolvimento de pensamento crítico e do importante hábito da leitura, de modo que o estudo de disciplinas como Filosofia, História e Literatura adquirem um estatuto tão importante como o obtido ao longo do tempo pela Matemática ou pela Física, as principais disciplinas privilegiadas nas escolas de orientação tecnocrática, ou seja, grande parte das instituições educacionais brasileiras.

Devemos ressaltar que esse tipo de estrutura educacional possibilita um diálogo enriquecedor tanto da Filosofia com as demais ciências humanas, através da realização de atividades que agregam em seu núcleo a visão filosófica de mundo com a disciplina que dialoga criativamente com ela. Por exemplo, se pensarmos numa associação entre Filosofia e Literatura, poderíamos analisar a obra literária de Machado de Assis, interpretando não apenas o estilo empregado pelo autor, as minúcias da sua narrativa, mas também as influências teóricas presentes de modo explícito na sua construção literária, como o importante legado schopenhaueriano, um certo pessimismo na sua analise descritiva das personagens, dentre outras possibilidades teóricas. Inclusive, em determinadas circunstâncias, torna-se até mesmo possível realizar uma interação entre a Filosofia e as disciplinas consideradas exatas, fato este que demonstra o vínculo primordial que existe entre o pensamento filosófico e a Matemática, por exemplo, vínculo esse que, conforme vimos anteriormente, fora esquecido pela tradição científica. Nessas instituições, se torna muito mais interessante e enriquecedor, não apenas para o estudante, mas também para o próprio professor de Filosofia, essa interação educacional entre o pensamento filosófico e as demais áreas de conhecimento. (4)

Portanto, a reflexão filosófica, seja ensinada através do método histórico, seja ensinada pelo método de interpretação de conceitos, quando desenvolvida adequadamente pelo professor, de acordo com as possibilidades oferecidas pelo espaço escolar, favorece sensivelmente a formação e criação de novos conceitos tanto pelo estudante, como pelo educador. Assim, podemos afirmar que ambos recolhem, por meio dessa interação com a obra filosófica, os conteúdos que despertam em suas consciências o senso crítico em relação aos problemas existentes na vida em sociedade, a compreensão das questões teóricas que se encontraram presentes nas diversas manifestações culturais da sociedade. Quando se utiliza a reflexão filosófica de modo a favorecer ao estudante o desenvolvimento da consciência crítica e da compreensão das peculiaridades sociais em todas as suas manifestações, os resultados desse processo serão certamente extremamente 
benéficos para o jovem estudante, posto que ele, por meio desse nível de conhecimento entrelaçado com a vida, sentirá nas suas disposições de ânimo uma necessidade cada vez maior por obter instrução, mais conhecimento. Contudo, essa busca pela aquisição do saber não ocorrerá através de um enfoque eruditista, ou seja, com o sujeito do conhecimento apenas buscando o "conhecimento pelo conhecimento", atitude que seria certamente prejudicial para o indivíduo, pois ele se tornaria tão somente um depósito de informações, desprovido da capacidade plástica de buscar alcançar um conhecimento que proporcione a sua ação. Pois o conhecimento genuíno possui um caráter lúdico, sendo assim um exercício que agrada, ainda que exija por parte do indivíduo uma grande dedicação e esforço. Afinal, se porventura analisarmos a característica do homem dotado de visão filosófica de mundo, constataremos que sua busca pelo saber decorre diretamente de um sentimento de afeição pelo mesmo, de modo que esse indivíduo se caracteriza por estar sempre procurando desenvolver cada vez mais a sua sabedoria de vida, demonstrando assim que a Filosofia não é apenas uma reflexão formal sobre temas abstratos, mas a associação entre esses conteúdos teóricos com a própria prática de vida, preenchida pelo sentimento de criação.

\section{Considerações Finais}

Estas reflexões acerca da importância do estudo de Filosofia para a vida humana e para o desenvolvimento criativo do pensamento crítico na consciência individual decorrem da minha interpretação pessoal do problema cultural sofrido pela sociedade brasileira, caracterizada, de uma maneira geral, pela desvalorização do autêntico ofício do ato de pensamento e da busca do conhecimento não como um recurso para a obtenção da realização pessoal, mas para a concretização de objetivos utilitários, afastados da vida prática individual. Em nome da obtenção de informações superficiais (as quais, conforme o próprio nome diz, somente informam, sem que necessariamente instruam, possibilitando a aquisição de um conhecimento genuíno), o indivíduo abdica do direito de pensar, para que possa então apenas repetir discursos pronunciados por terceiros, fato este que denota explicitamente a sua incapacidade de pensar e julgar com autonomia.

Uma vez que a Filosofia essencialmente se desenvolve através do diálogo, da interação, da crítica e da inovação dos conceitos, considero como uma afronta ao desenvolvimento do conhecimento humano o espaço reduzido para debates que lhe é dedicado em nossos meios sociais, sobretudo nas escolas, de modo que a reflexão filosófica consistente é negligenciada por fatores estranhos ao próprio universo genuíno da cultura. Consequentemente, podemos nos indagar: de que adiantaria o indivíduo receber uma instrução tecnicista de grande qualidade dentro deste ramo epistêmico, se ele não é capaz de refletir acerca do melhor modo de conduzir a sua vida prática? $\mathrm{O}$ exercício de pensamento filosófico possibilita a formação de uma consciência pessoal e social, adequada para a formação de uma cidadania pautada na compreensão da singularidade individual de cada ser humano, jamais a massificação do homem, inserido na esfera da impessoalidade, do anônimo. $\mathrm{O}$ desenvolvimento de uma consciência filosófica garante ao indivíduo a aquisição do conhecimento pautado no senso de criatividade e na valorização da potencialidade pessoal. Podemos considerar então que a Filosofia 
não é apenas um exercício despropositado de pensamento, divorciado do mundo da vida; pelo contrário, é a principal possibilidade de compreensão deste.

\section{Referências}

NIETZSCHE, Friedrich. Consideração Intempestiva III: Schopenhauer Educador, In: Escritos sobre Educação. Trad. de Noéli Correia de Melo Sobrinho. Rio de Janeiro: Loyola/PUC-Rio, 2003.

(1) Mestrando em Filosofia - UFRJ/Bolsista do CNPq

E-mail: renunbitt2@yahoo.com.br

(2) Gostaria de informar que utilizo esse espaço para destacar que considero como "burocratas do ensino" os indivíduos caracterizados sobretudo pelo fato de inserirem no processo de organização da estrutura de ensino e na transmissão do mesmo interesses completamente estranhos ao desenvolvimento adequado da cultura. Desse modo, o "burocrata do ensino" se assemelha profundamente ao tipo de homem que os críticos e os filósofos denominavam outrora como o "filisteu da cultura", aquele que é sobretudo incapaz de diferenciar as questões genuinamente culturais das questões de âmbito econômico e burocrático.

(3) Nesse ponto, podemos nos beneficiar da interpretação de Nietzsche acerca do antagonismo entre o "filósofo intempestivo", aquele cujo modo de viver e de pensar se contrapõe ao sistema massificador da cultura de sua sociedade, e o Estado, o grande legitimador da decadência da cultura: "Em todo lugar onde houve poderosas sociedades, governos, religiões, opiniões públicas, em suma, em todo lugar onde houve tirania, execrou-se o filósofo solitário, pois a filosofia oferece ao homem um asilo onde nenhum tirano pode penetrar. A caverna da interioridade, o labirinto do coração: e isto deixa enfurecido os tiranos." [Cf. NIETZSCHE, Friedrich. Consideração Intempestiva III: Schopenhauer Educador, § 3, p. 156].

(4) Ressalto que esse método extremamente benéfico para a formação educacional do estudante, assim como para o sentimento pedagógico do professor, se desenvolve sobretudo no Colégio Pedro II, no Rio de Janeiro, instituição federal que serve como referência para a educação brasileira ao nível fundamental e médio. 